\author{
Cadernos de \\ ESTUDOS LINGUÍSTICOS - (59.1), Campinas, pp. 37-52 - jan./abr. 2017
}

\title{
DEFINITE DESCRIPTIONS, PRESUPPOSITIONS AND REFERENCE ${ }^{* 1}$
}

\author{
MARCO RUFFINO
}

\begin{abstract}
In this article I review some fundamental aspects of the singularist view of definite descriptions taking as paradigm the Frege-Strawson version of it. I consider more closely the role of the definite article and its relation with presuppositions. Finally, I raise some doubts about the coherence of such approach as an explanation for the phenomenon of reference.
\end{abstract}

Keywords: definite descriptions; reference; presuppositions.

RESUMO: Neste artigo reviso alguns aspectos fundamentais da perspectiva singularista de descrições definidas tomando como paradigma a versão de Frege-Strawson. Em seguida considero mais detalhadamente o papel semântico do artigo definido e sua relação com pressuposições. Finalmente, levando algumas dúvidas sobre a coerência da perspectiva singularista enquanto explicação do fenômeno da referência.

Palavras-Chaves: descrições definidas; referência; pressuposições.

There are a number of classical philosophical approaches to definite descriptions. Among them we have the proposals of Frege (1892), Russell (1905, 1912), Hilbert and Bernays (1934), Strawson (1950), Donnellan (1966), Kripke (1980), Barwise and Cooper (1981), Evans (1982) and Neale (1990), to mention only a few. Roughly speaking, despite their many differences, they all can be counted as belonging to one of two broad groups: those who think that definite descriptions are singular terms (i.e., can be used for singular reference) and those who think that they are something else. I will refer to the view of the firs group (i.e., that descriptions are singular terms and thereby can be used for singular reference) as singularism. Some singularists claim that definite descriptions can be so used (although there might be other non-referential uses) ${ }^{2}$; some claim that they must be so used (i.e., the only possible use) ${ }^{3}$. It is harder to find a term for the second group, since there is not one single analysis of descriptions as non-singular terms.

\footnotetext{
"Universidade Estadual de Campinas, Campinas (SP), Brasil. ruffinomarco@gmail.com

${ }^{1}$ Research for this paper was supported by grant 301721/2013-0 from CNPq (Brazil).

2 E.g., Strawson (1950) and Donnellan (1966).

${ }^{3}$ E.g., Frege (1892) and Hilbert and Bernays (1934).
} 
Some think that they are binary quantifiers ${ }^{4}$, some think that they are generalized quantifiers ${ }^{5}$, some think that they are syncategorematic expressions and disappear under a deeper analysis 6 .

In this paper I want to raise some additional doubts about singularism motivated from considerations about the internal coherence of the prototypical singularist theories. I will take as prototypical the Frege-Strawson approach, although I do not mean to imply that there is no interest in the other variations of singularism, nor that the Frege-Strawson has no interest at all. On the contrary, it has strong interest in that it gives rise to the contemporary theories of presuppositions. What I mean is that it fails to account for the referential character of descriptions in terms of presuppositions. Or so I shall argue. The paper is so divided: in the first section I review the main points of Strawson's criticism of Russell's theory of definite descriptions, and the genesis (or the reformulation, if we consider that the idea has a precursor in Frege) of presuppositions as central elements in the act of referring. In the second section I consider some important restrictions on the sort of definite descriptions that is under discussion. In the third section I review the contemporary distinction between semantic and pragmatic presupposition, and discuss which of them is behind Strawson's view. In the fourth section I raise some preliminary worries about the relation between presuppositions and reference for the Frege-Strawson alternative. In the fifth section I review Donnellan's explanation of reference and referential use of definite description, and claim that it captures something essential about the use of definite descriptions as referential devices. I conclude that presuppositions (or the fulfillment of presuppositions) cannot give us what is required for referring, thereby casting doubt on the FregeStrawson combination of descriptive role and referential role of descriptions.

A terminological note: although there are also indefinite descriptions (or what Russell (1912) calls "ambiguous descriptions", i.e., phrases such as 'a man', 'some teacher', etc.), for the sake of brevity, I shall use 'descriptions' from now on to refer only to definite descriptions.

\section{STRAWSON ON REFERENCE AND PRESUPPOSITIONS}

Strawson (1950) famously attacks Russell's theory of descriptions, in particular two essential aspects of it. According to Russell (1905), whenever a description $x$ ) $T x^{77}$ occurs in a sentence ' $\Phi(x) T x$ )' (where $\Phi$ can be seen as any predication of $x$ ) Tx' or, more generally, as any open formula), the sentence has to be seen as expressing three statements, i.e., first that there is at least one $T(x T x)$, second that there is at most one $T()$ and, finally, that whatever is $T$

\footnotetext{
${ }^{4}$ E.g., Evans (1982).

${ }^{5}$ E.g., Barwise and Cooper (1981) and Neale (1990).

${ }^{6}$ E.g., Russell (1905, 1910).

${ }^{7}$ I use Russell's notation of the inverted-iota as formal representation for the definite article.
} 
is also $\Phi((\Phi x))$. Combining the three statements we have that ' $\Phi(x) T x)^{\prime}$ ' is equivalent to $x(T x \mathrm{~F} x)^{\prime}$. But the former seems like a subject-predicate sentence, while its analysis as the latter does not have this form since it is an existential sentence, and contains no singular terms, but only quantifiers and predicates. What happens, according to Russell, is that sentences containing descriptions only appear to be of the subject-predicate form, but this is a misleading effect of the superficial grammatical form. In fact, definite descriptions are not singular terms, but syncategorematic terms, i.e., only the sentence as a whole containing the description can be analyzed, and the description itself disappears upon analysis. ${ }^{8}$ So, the two crucial features of Russell's account that Strawson denies are: (i) descriptions are not referential devices, since sentences containing them are not of the subject-predicate form, but are actually existential claims; (ii) existence and uniqueness are part of the content of definite descriptions (or, better said, of sentences containing them). There are three main critical points against Russell's theory of descriptions that are relevant in our discussion:

1-By far the most important criticism is directed to the claim that a sentence ' $\Phi(x) T x$ )' contains in its semantic content (or, in its deep structure) the statement of existence and uniqueness of a $T$. In Russell's view, a sentence such as 'The present king of France is bald' (uttered today, when France is no longer a monarchy and has no King) is not meaningless, but simply false, since one of the conjuncts (existence) is false. ${ }^{9}$ However, Strawson objects that existence and uniqueness are not really part of the content, but are mere presuppositions that have to be true if the sentence is to have a truth-value at all (being otherwise neither true nor false). I say that this is the most important point because it motivated the systematic study of presuppositions in contemporary philosophy and linguistics. The original view of existence and uniqueness as presuppositions backing description, rather than part of the content of them,

\footnotetext{
${ }^{8}$ For Russell, only what he describes as logically proper names are genuine singular terms. These names have no other content besides the object referred to. Hence, their meaning depend on the presence of the referred object.

${ }^{9}$ Russell claims that his analysis is sound because it solves three difficult puzzles involving descriptions. The first puzzle is generated by the substitution of descriptions such as 'the author of Waverley' by co-referential names such as 'Scott' in propositional attitude reports such as 'George IV wished to know whether Scott is the author of Waverley'. While the first report is true, the resulting report, i.e., 'George IV wished to know whether Scott is Scott' is false, although both seem to be about the same object (Scott, who is also the author of Waverley). The second puzzle is the apparent violation of the law of excluded middle in cases of descriptions that correspond to nothing. E.g., 'The present King of France is bald' is not true (since the present King of France is not in the set of bald people), but it is not false either (because the present King of France is also not in the set of hairy people). The third puzzle comes from an apparent contradiction in every negative existential statement involving empty descriptions, e.g., 'The present King of France does not exist'. Since the statement is meaningful, the property of non-existence must be attributed to something (i.e., an existing entity), for otherwise the statement would be meaningless.
} 
comes from Frege..$^{10}$ But, as it happens many times when dealing with aspects of natural language, Frege does not pay much attention nor tries to develop it since, for him, most aspects of natural language are on the same level as vagueness and ambiguity, i.e., are seen as a kind of defect to be avoided in a formal language. ${ }^{11}$ It was Strawson's reformulation of these ideas that called attention to the phenomenon of presupposition more broadly. ${ }^{12}$

2-According to Strawson, one must distinguish the meaning of an expression from its reference. ${ }^{13}$ Hence, 'the present King of France' has a meaning independently of having a reference. Meaning is a property of expression-types, while reference is a feature of expression-tokens. But descriptions might be used in the same way that names and demonstratives are, i.e., to make reference to particulars. Although the meaning of a description is perennial, it might have a referential use at some times and lose this use in some other times. E.g., 'the present King of France' had a referential use many times in history (e.g., in the XVIIth century), but lost this particular function in the XXth century, although the meaning remains the same.

\section{3-Reference is not something that the expression itself does, but rather something} that the speaker does by uttering the expression. ${ }^{14}$

${ }^{10}$ In "Über Sinn und Bedeutung" (1892) Frege's famously excludes existence from the official content of a description, e.g., in the following passage:

The sense of the sentence 'After Schleswig-Holstein was separated from demark, Prussia and

Austria quarrelled' can be rendered in the form 'After the separation of Schleswig-Holstein from

Denmark, Prussia and Austria quarrelled'. In this version, it is surely sufficiently clear that the sense is not to be taken as having as part the thought that Schleswig-Holstein was once separated from Denmark, but that this is the necessary presupposition in order for the expression 'after the separation of Schleswig-Holstein from Denmark' to have a Bedeutung at all. $(1892,42 \mathrm{n}$. J)

$\mathrm{He}$ is less explicit about uniqueness. But there are many passages in which he mentions both existence and uniqueness as two equally important conditions for the legitimate use of definite descriptions, without indicating that he sees any asymmetry between them. Hence, he most likely sees uniqueness as a presupposition as well. Some contemporary theories of presupposition tend to focus only on existence, while uniqueness is not presupposed, but is part of the content. This was most likely not Frege's view.

${ }^{11}$ In the formal language of Grundgesetze der Arithmetik (1893, § 11), Frege completely avoids the need of presuppositions by adopting a first-order operator as substitute for the definite article. This operator is such that, if the argument is a singleton set, it gives the unique element as its value. If the argument is any other object, the value given is the object itself.

${ }^{12}$ Soames (1976) suggests that Strawson is probably not aware that his theory of presupposition has a precursor in Frege.

${ }^{13} \mathrm{He}$ seems to have in mind something similar to Frege's distinction between sense ("Sinn") and reference ("Bedeutung").

${ }^{14}$ There is one additional point raised by Strawson that has only marginal interest for our discussion, although it gave rise to an intense debate in the literature about descriptions. According to Russell's analysis, the employment of a description implies that there is only one object satisfying the descriptive content (uniqueness). However, Strawson claims, on many occasions there is no such presumption. If one says 'The table is covered with books', the description 'the table' refers to a particular table, although no one assumes that there is only one table in the world. This is known nowadays as the problem of incomplete descriptions, i.e., descriptions that are apparently used 


\section{PURELY DESCRIPTIVE NON-QUESTION-BEGGING DESCRIP-} TIONS

Of course the question about existence and uniqueness would be trivialized if one of these conditions or both were already part of the descriptive content itself. E.g., if we are considering descriptions that are not of the form 'the Tasmanian tiger' but of the form 'the only Tasmanian tiger' or 'the existing Tasmanian tiger' or (to include both of them in the logical form) 'the uniquely existing Tasmanian tiger' to be formally represented, respectively, as
$\mathrm{x}) \mathrm{Tx}$
$\mathrm{x})($ Tx $y($ Ty $x=y))$
$\mathrm{x})(\mathrm{Tx} \mathrm{y}(\mathrm{x}=\mathrm{y}))$
$\mathrm{x})($ Tx $y(x=y) y($ Ty $x=y))$

Although these conditions might be included in the logical form, the traditional and relevant question is whether descriptions that do not have these clauses somehow imply or presuppose existence and uniqueness. I shall therefore restrict our discussion to descriptions that do not contain in its syntactical form a clause of existence or uniqueness. In other words, the question is how purely descriptive descriptions relate to the corresponding statements of existence and uniqueness.

There is also a second restriction to be made concerning descriptions in relation to reference. Donnellan (1970) points out that some of them are questionbegging because they already contain, in their descriptive content, the notion of reference (of the name or of the description) itself. For example, 'the entity I have in mind', 'the entity I refer to', 'the entity referred to by 'Aristotle". He formulates the condition that "the descriptions that 'back up' the use of a name should not be "question-begging"” (p. 61). Kripke (1980) raises a similar point: some descriptions are circular because their descriptive content already embodies one way or another the notion of reference. Hence, if one is to look for the reference of "the person referred to by "Aristotle", one has to know already what the reference of the description is in order to apply its descriptive content as a guide to the reference. Kripke formulates a non-circularity condition for any acceptable form of descriptivism ${ }^{15}$ as "The properties which are used in the vote must not themselves

\footnotetext{
referentially but, nevertheless, fail to semantically specify a unique object. Sellars (1954) suggests that an expression such as 'the table' is actually incomplete, and when employed must receive a grammatical complement contextually supplied such as 'the table over there' or 'the table in room 21', which are then complete descriptions, and there is one and only one object falling under the descriptive content. If one treats descriptions not as referential devices but as quantifiers, the point raised by Strawson is a particular form of the problem of quantifier domain restriction in natural language. (About this issue, see Stanley and Szabó (2000) and Ruffino (2009).)

15 Actually part of Kripke's conclusion in (1980) is that no form of descriptivism is acceptable. What I mean to say is that non-circularity is, according to Kripke, a condition for formulating the strongest possible form of descriptivism which is then object of his attack.
} 
involve the notion of reference in such a way that it is ultimately impossible to eliminate" (1980, p. 71). Following both Donnellan and Kripke, I want to restrict the discussion in this paper to those descriptions that are non-question-begging (or non circular), i.e., descriptions that include in their descriptive content only ordinary properties identifying objects, but not being the reference or term of any semantic relations with the description itself.

\section{PRESUPPOSITION: SEMANTIC AND PRAGMATIC}

The theory of presupposition is motivated by two kinds of phenomena that call for theoretical explanation. First is the fact that speakers might show hesitation as to whether sentences such as the following are true or false:

(1) The mathematician who proved Goldbach's conjecture is a woman.

(2) The engineer who designed the Alps had a good sense of aesthetics.

Given the fact that there are no individuals corresponding to the description, speakers might be reluctant to consider the sentences false, and at the same time recognize that they are not true either. Speakers are reluctant because the following two sentences

(3) Someone proved the Goldbach's conjecture.

(4) Some engineer designed the Alps.

are false, but the truth of (3) seems to be a necessary condition for (1) to be true or false, while the truth of (4) seems to be a necessary condition for (2) to be true or false. We might call this phenomenon the Truth-Value Gap Intuition. ${ }^{16}$ The second phenomenon is that, although some semantic features of parts of a sentence might change when the latter is embedded in some contexts, the presuppositions tend to survive the embedment in several contexts. For example, the existence of a

16 This, again, has a precursor in Frege:

Now languages have the fault of containing expressions which fail to designate an object (although their grammatical form seems to qualify them for that purpose) because the truth of some sentence is a prerequisite. Thus it depends on the truth of the sentence 'There was someone who discovered the elliptic form of the planetary orbits' whether the subordinate clause 'The one who discovered the elliptic form of the planetary orbits' really designates an object, or only seems to do so while in fact is bedeutungslos. And thus it may appear as if our subordinate clause contained as a part of its sense the thought that there was somebody who discovered the elliptic form of the planetary orbits. If this were right, the negation would run: 'Either the one who discovered the elliptic form of the planetary orbits did not die in misery or there was nobody who discovered the elliptic form of the planetary orbits'. (1892, p. 40)

The last sentence is clearly meant as a reductio. Atlas (1975) points out that, in this argument, Frege seems to assume that the only form in which existence could be part of the content of the sentence is as one of its conjuncts. 
designer of the Alps is a presupposition of all the following sentences (in which the original one is embedded):

(5) The designer of the Alps does not have a good sense of aesthetics

(6) If you've ever seen the Alps you have the feeling that its designer has a good sense of aesthetics.

(7) Nobody prevented me that the designer of the Alps has a good sense of aesthetics.

This phenomenon is normally called Projection, and the embedment of a sentence under operators normally inherit that sentence's presuppositions except under the presence of those operators that Karttunen (1973) calls plugs or filters (which, respectively, block or limit the projection).

Strawson thinks that the Truth-Value Gap Intuition is the most natural one:

Now suppose someone were in fact to say to you with a perfectly serious air: The King of France is wise. Would you say, 'That's untrue'? I think it is quite certain that you would not. But suppose that he went on to ask you whether you thought that what he had just said was true, or was false; whether you agreed or disagreed with what he just said. I think you would be inclined, with some hesitation, to say that you did not do either; that the question of whether his statement was true or false simply did not arise, because there was no such person as the King of France. You might, if he were obviously serious [...] say something like: 'I' $m$ afraid you must be under a misapprehension. France is not a monarchy. There is no King of France. (1950, p. 330). ${ }^{17}$

Russell does not share this perspective. Of course the main argument for his analysis is not its intuitive appeal but the potential for solving puzzles. He even mentions at the very end of Russell (1905) that the reader might be tempted to make up his mind against his view "on account of its apparent excessive complication" (p. 493), apparently admitting a certain degree of counter-

${ }_{17}$ On the other hand, Strawson himself in later writings points out that the intuitive feeling of truth-value gaps might disappear under some uses of descriptions for which the presuppositions fail. Here are some examples:

Suppose, for example, that I am trying to sell something and say to a prospective purchaser The lodger next door has offered me twice that sum, when there is no lodger next door and I know this. It would seem perfectly correct for the prospective purchaser to reply That's false, and to give as his reason that there was no lodger next door. And it would indeed be a lame defense for me to say, Well, it's actually not false, because, you see, since there's no such person, the question of truth and falsity doesn't arise (1954, p. 225).

Suppose I am ignorantly boasting about my friend's visit to Rome and mention the King of France as one among the distinguished people he had seen there. I might say He had lunch with the prime minister, had an audience with the pope, and then went for a drive with the King of France. Someone might say, Well, at least this is false (not true) that he went for a drive with the King of France-for there is no such person. (1954, p. 226)

von Fintel (2004) argues that these examples constitute only apparent exceptions to the existence of truth-value gaps under failure of presupposition, and provides alternative explanations for the rejection of sentences as false. Actually, von Fintel considers truth-value intuitions, including the gap intuition, as non-fundamental. 
intuitiveness in his account. But sometimes he does appeal to the speaker's intuitions as well (especially in replying to Strawson):

Suppose, for example, that in some country there was a law that no person could hold public office if he considered it false that the Ruler of the Universe is wise. I think an avowed atheist who took advantage of Mr. Strawson's doctrine to say that he did not hold this proposition false would be regarded as a somewhat shifty character. (1959, pp. 243-4)

In other words, Russell would deny that there is such as thing as the Truth-Value Gap Intuition. It might seem that the choice between Russell's and Strawson's analysis is to be solved by a battle between conflicting intuitions. However, as von Fintel (2004) argues, this is not so. The theory of presuppositions has an independent theoretical interest and that is not just a matter of intuition. First, besides the direct appeal to intuitions, there are some tests that one can apply to check whether presuppositions are made. For example, a test of whether an utterance of $\mathrm{S}$ presupposes $\mathrm{P}$ can be formulated in terms of the plausibility of the audience's reactions of the form 'Hey, wait a minute, I didn't know that P'. ${ }^{18}$ (If the reaction is admissible, then $\mathrm{P}$ is a presupposition.) But second, and more importantly, intuitions concerning truth-value gaps play only secondary role, and the primary role must be intra-theoretic, i.e., the justification must come from the plausibility and fruitfulness of a theory in explaining the many aspects of presupposition projections:

[W]hether a sentence with a failed presupposition is judged false or arouses feelings of squeamishness depends on the intricacies of a peculiar fall-back strategy which cares about having salient footholds for rejection. The pattern of truth-value judgments we discovered cannot serve as a direct diagnostic for the presence or absence of presuppositions. The right theory of presuppositions will most likely be one that best explains patters of presupposition projection, as most researchers have always assumed. (2004, p. 341).

Current linguistic theories (e.g., Keenan (1971), Levingson (1983), Stalnaker (1970)) commonly distinguish between two different sorts of presuppositions. On the one hand, we can talk of the semantic presupposition of a sentence $\mathrm{S}$ as what is involved if $\mathrm{S}$ is to be true or false. (If the presupposition fails, than $\mathrm{S}$ is neither true nor false.) Strawson himself gives the following definition of $\mathrm{S}$ has $\mathrm{S}$ ' as a semantic presupposition (although he does not call it so): “The truth of $S$ ' is a necessary condition of the truth or falsity of S" (1954, p. 216). Semantic presupposition is, hence, a relation that has sentences or propositions as relata. On the other hand, we can talk of the pragmatic presupposition of $\mathrm{S}$ as a belief or set of background beliefs, i.e., sentences (or propositions) whose truth the speaker takes for granted in an assertion. Stalnaker expresses the most salient distinguishing feature of the pragmatic notion in the following way:

According to the pragmatic conception, presupposition is a propositional attitude, not a semantic relation. People, rather than sentences or propositions, are said to have, or make, presuppositions

${ }^{18}$ Shanon (1976) proposes a similar test for presuppositions. 
in this sense...To presuppose a proposition in the pragmatic sense is to take its truth for granted and assume that others involved in the context do the same. (1970, p. 38)

Pragmatic presupposition is, hence, a relation that necessarily has two kinds of relata, one of them being sentences or propositions and the other one being a belief or set of beliefs.

Which one of these notions of presuppositions Strawson has in mind in his criticism of Russell? Does it make a difference for the theory of descriptions? Sellars (1954) correctly complains that Strawson is not quite clear about what exactly is involved in presupposing something, i.e., whether it is something that speakers do (propositional attitudes) or whether it is a relation between sentences (or propositions). Strawson indeed seems to bounce between the semantic and the pragmatic notion; in this aspect, he reproduces Frege's ambiguity concerning presuppositions. ${ }^{19}$ Here is a passage in which Strawson replies to Sellars' complaint:

"S presupposes S" is defined as follows: "The isepitruth of $S$ ' is a necessary condition of the truth or falsity of S." It will be noted that this definition [has the consequence that $S$ ' is not in any ordinary sense a component of what is asserted by S. It will also be noted that the definition makes no reference at all to the beliefs of speakers or hearers. It does, however, have the fairly obvious consequence that, where S presupposes S', it would be incorrect (or deceitful-the cases are different) for a speaker to assert S unless he believed or took for granted that S'. (1954, pp. 216-7)

Stalnaker (1970) suggests a kind of bridging principle between semantic and pragmatic presuppositions: a sentence with a certain semantic presupposition can be used in communication only if the truth of the latter is taken for granted by both the speaker and the audience. In other words, every semantic presupposition is also a pragmatic presupposition, although the converse might not be true (i.e., the speaker might have beliefs that are not a semantic presupposition). I take it that something like Stalnaker's bridging principle is behind Strawson's ambiguity, i.e., he seems to assume that whatever is required for a sentence to have a truth-value (semantic presupposition) is also something that the speaker believes (pragmatic presupposition) if he sincerely utters that sentence. At least the passage above suggests this interpretation.

\section{PRESUPPOSITION AND THE COHERENCE OF THE FREGE- STRAWSON FRAMEWORK}

One of the interests of the Strawson-Frege perspective is that it brings into question the semantic role of the definite article and its relation to presuppositions. If we take for granted that $x$ ) $T x$ ' the semantic role of ' $T$ ' is to refer to a concept (simple or complex), than we might ask what exactly is the semantic role of ' $x$ )'. If one considers the role of ' $x$ ) Tx' as referential, i.e., as having an object as

\footnotetext{
${ }^{19}$ See, e.g., Atlas (1975).
} 
semantic value, then a first suggestion could be that ' $x$ )' corresponds to a secondorder operator that takes concepts onto objects. This is the way that, e.g., Dummett (1973) interprets the definite article in Frege's semantics: a second-order operator on a pair with the number-operator ' $N x$ : $\Phi x$ ' that associates with each concept $F$ a number (i.e., the number of instances of $F$ ), and the abstraction operator $\{x$ : $\Phi x\}$ that associates with each concept $F$ the set of instances of $F$. But this explanation of the definite article can be interesting only if the operator contains a rule or instruction to associate the concept $F$ with the uniquely existing $F$. Otherwise, the definite article would be an entirely arbitrary operator, that associates simply by coincidence the only existing $F$ to the concept $F$. In other words, the definite article must contain somehow, as part of its content, existence and uniqueness as guides for associating a value to any concept. But this is, as we know, something that Frege denies: the sense of a definite description does not contain the claim of existence (or uniqueness); this is only presupposed, but not part of the content. In this aspect, the definite article is entirely different from the numerical and the abstraction operator: while it can be part of the sense of ' $N x$ : $\Phi x$ ' that, for any concept $F$, the number of $F$ is the value to be associated with it, and it can be part of the sense of $\{x: \Phi x\}$ that, for any concept $F$, the extension of $F$ is the value to be associated with it, it cannot be part of the sense of $x$ ) $\Phi x^{\prime}$ that, for any concept $F$, the only existing $F$ is the value to be associated with it.

According to Strawson, the definite article in a description does not say or imply (in any strong logical sense) existence or uniqueness, but is merely a marker or indicator that the corresponding presuppositions are made:

But one of the conventional functions of the definite article is to act as a signal that a unique reference is being made - a signal, not a disguised assertion. When we begin a sentence with "the such-and-such" the use of "the" shows, but does not state, that we are, or intend to be, referring to one particular individual of the species "such-and-such". (p. 331) 20/21

But this raises a worry about the internal coherence of the Frege-Strawson perspective: the presence of the definite article in descriptions indicates a

${ }^{20}$ To be fair, Strawson does not say in this passage that being a presupposition indicator is the unique conventional function of the definite article (which is in principle consistent with having some semantic value), but "one of the conventional functions". But he does not mention any other conventional function, so I take it that marking a presupposition is, if not the only, at least the most important function of the definite article for him.

${ }^{21}$ Strawson's view of the definite article as a mere indicator (i.e., as showing something, without having a reference) has a precursor in Frege as well. In a footnote that occurs only in the unpublished version of "Über Begriff und Gegenstand" (which the editors of Frege's Nachlass placed together with the published version), Frege says:

The definite article does not add a new characteristic mark. What it does do is to indicate ["liegt in ihm angedeuted"]: (1) That there is such a result. (2) That there is only one such. (NS p. 110/ PW p. 100; my emphasis.)

The verb "Andeuten" in German is weaker than "bedeuten". As I understand Frege, the "new characteristic mark" that the definite article does not add is any second-order operator. I.e., the definite article does not refer to a second-order operator that, together with a first-order concept, yield an object (the reference of the description). It only indicates that the presuppositions are fulfilled. 
presupposition on the speaker's part which is, supposedly, attached to a descriptive content. And, as we saw, presupposition is something that the speaker does, it is a propositional attitude. But in which sense can a presupposition transform a descriptive content into a singular one? A mere expectation or belief or intention can hardly transform a descriptive content into a singular content. (In the Fregean framework, this would correspond to the transformation of an unsaturated sense of a conceptual expression into a saturated singular sense; but this cannot be done by an attitude or expectation on the speaker's part, since only senses can combine with senses in order to build complex senses. $)^{22}$ But if this is so, the singular content has to appear on its own, without any fundamental connection with the descriptive part. This is hardly coherent with a compositional view of the singular content as build from the descriptive content together with the definite article. In other words, this way out is not clearly compatible with compositionality.

\section{HAVING DONNELLAN IN MIND}

In a series of two celebrated articles, Donnellan (1966 and 1970) paves the way to the revolution that was about to happen in philosophical semantics against the Fregean paradigm. The first one deals basically with descriptions, and introduces a way of looking at them that, although quite natural and well supported by empirical data, had gone unnoticed by the philosophical tradition. The second one deals with proper names in their relation to descriptions, and anticipates some of the views later developed by Kripke in Naming and Necessity (1980). They represent not only a radical shift of perspective in the semantics of singular terms, but also capture, in my view, some essential aspects of the phenomenon of singular reference.

In the first paper (1966) Donnellan argues for two main theses. The first one is that descriptions do not work in one single uniform way but might have two quite distinct uses, one that Donnellan calls referential, and the other one that he calls attributive. Attributive use is made when the speaker does not have in mind any specific individual as referent but whatever uniquely satisfies the descriptive content. A good example is that in which a police detective, seeing the scene of a violent murder of someone called 'Smith', and before coming to know who the

${ }^{22}$ One theoretical alternative is to treat definite descriptions as quantifiers with a radical restriction of the quantifier domain (Hawthorne and Manley (2010)). There are different kinds of explanation of the restriction, some of them appealing to the semantics of the quantifier (like a hidden variable to be filled in each context with a restricted domain as suggested, e.g., by Stanley and Szabó (2000)), some of them to a grammatical supplementation of the descriptive expression in each context (e.g., Sellars (1954)), some of them to the pragmatic transformation of a proposition literally expressed with unrestricted domain into a proposition communicated with a restricted domain (e.g., Cappelen and Lepore (2005)), and some of them to a pre-semantic role of speaker's intention (Ruffino 2015). But this theoretical alternative has as consequence that singular thought using descriptions is ultimately impossible. Indeed, Hawthorne and Manley are happy with that consequence since part of the point of their book is to launch an attack on the very notion of singular thought. 
murderer is, says 'Smith's murderer is insane'. There is no particular individual that the detective has in mind in using the description 'Smith's murderer': he wants to say something of a non-specified individual that satisfies the descriptive content. In cases like this, it is essential that there is one and only one individual satisfying the description for the uttered sentence to have a truth-value. If there is no such individual, the sentence is neither true nor false, and an order like 'Bring me Smith's murderer right now' cannot be followed. On the other hand, if the use is referential, the speaker has a particular individual in mind when employing the description, and it is not essential that that individual satisfies (or uniquely satisfies) its descriptive part. For example, in a trial in which someone is being accused of murdering Smith, the same detective in the public might want to comment on the defendant's strange behavior by saying 'Smith's murderer is insane'. In this case the person referred to is the defendant, no matter whether he really is Smith's murderer (or whether anyone at all is Smith's murderer). What the detective said was true (or false) because it concerns that particular individual (the defendant), independently of there really being anyone who fits the descriptive content. In other words, existence and uniqueness of an entity satisfying the descriptive content is not essential if the description is used referentially. The second thesis defended by Donnellan is that only the referential use of a description constitute reference properly speaking; the attributive use cannot count as reference because there is no particular object that the speaker wants to consider, but just a generic talk of something that exists and is unique.

In the second paper (1970) Donnellan discusses what he calls the principle of identifying description, i.e., the idea that there is a description (or a set of descriptions) backing proper names, and the reference of these names is always the object that uniquely satisfies the backing description (or set of descriptions). By means of a series of examples (similar to those employed in what later came to be known as Kripke's "semantic argument") Donnellan shows that the reference of ordinary names is quite independent from the descriptive content, and the link between the name and its referent has to be sought elsewhere. Here is a passage in which he very nicely explains the way he sees reference and its relation to descriptions:

To illustrate this, we can imagine the following games: In the first a player gives a set of descriptions and the other players try to find the object in the room that best fits them. This is analogous to the role of the set of identifying descriptions in the principle I object to. In the other game the payer picks out some object in the room, tries to give descriptions that characterize it uniquely and the other players attempt to discover what object he described. In the second game the problem set for the other players (the audience in the analogue) is to find out what is being described, not what best fits the descriptions. Insofar as the descriptions enter into a determination of what the referent of the name is, I suggest the second game is a better analogy. In that game, on the normal assumption that people are unlikely to be badly mistaken about the properties of an object they are trying to describe, the other players would usually first look for an object best fitting the description given. But that need not always be the best tactics. They may notice or conjecture that the circumstances are such that the describer has unintentionally mis-described the object, the circumstances being such as distortions in his perception, erroneous beliefs he is known to hold, etc. (p. 77) 
The main morals to be drawn from Donnellan's discussion in both papers (quite independently from accepting his own suggested model of a causal-historical explanation of the reference of names) is, first, that if there is reference at all in the use of a description, than this use must be referential (as opposed to attributive) and the satisfaction of the descriptive content is not essential and, second, that reference is an act on the speaker's part in which he first has some particular individual in mind and then try to get the audience to identify that individual with the help of a description (or set of descriptions). "Having in mind" is a necessary condition for the referential use of a description.

If we accept Donnellan's conclusions about descriptions and reference, as I think we should, there is a problem for the Frege-Strawson approach. (If we don't accept, the Frege-Strawson approach remains mysterious and gappy as an account of reference anyway.) As we saw, for the latter descriptions are both descriptive (because the descriptive ingredient is essential to it, i.e., an object cannot be the reference unless it uniquely fits the descriptive content) and referential (because they are referential devices). But there is no explanation of what bridges the descriptive and the referential use (or, to speak metaphorically, of how they "communicate"). The bridge cannot be given by presuppositions, for presuppositions are propositional attitudes, and propositional attitudes by themselves cannot, consistently with compositionality, turn a descriptive semantic content into a singular one. Neither can it be given by the fulfillment of the presuppositions (of existence and uniqueness), for this only means that an expectation on the speaker's part was fulfilled, but that has nothing to do with the semantic content. Moreover, the fact (or the belief) that both presuppositions are true, i.e., that there is one and only one object that has a certain property $F$, cannot turn the mind of the speaker from the thought of (or "reference" to) an unspecified object to the thought of (or reference to) a particular object. Existential or universal beliefs, even if they are true, are only existential or universal, but never singular. This might indicate that there is a fundamental gap between presuppositions or presuppositions-fulfillment and singular reference that the Frege-Strawson approach is unable to close. Another way to put it is that the four combined theses

(i) existence and uniqueness are mere presuppositions,

(ii) the role of the definite article is merely to indicate this presupposition (i.e., it does not mean a second-order operator that takes concepts onto objects),

(iii) the descriptive contents of descriptions are essential and

(iv) descriptions are referential devices

yield a theory that is either incoherent or leaves reference fundamentally unexplained. 


\section{CONCLUSIONS}

Strawson is not clear about which kind of presupposition (i.e., whether semantic or pragmatic) existence and uniqueness are in his approach. (In this he follows Frege's ambiguity.) This is perhaps not too bad, since there is a bridging principle between both kinds of presuppositions, as Stalnaker suggests (i.e., every semantic presupposition of $\mathrm{S}$ is also a pragmatic presupposition made by a speaker who sincerely utters S). But pragmatic presuppositions are propositional attitudes, and the particular kind of propositional attitude here involved cannot confer a semantic value to the definite article. Neither can it place the speaker in a state of mind focusing one particular object. Some negative consequences for the FregeStrawson approach seem to follow: first, that we are thereby left in the dark as to how the descriptive content of a description turns into a singular content (or, if one wants, how the descriptive content combines with the semantic value of a definite article to yield a singular content because there is no such semantic value). Second, if one regards having in mind (in Donnellan's sense) as something essential for reference, then there is no explanation of reference of descriptions in the Frege-Strawson approach. There is a third, more dramatic conclusion: if one takes the standard interpretation of Frege's doctrine of singular terms and consider all of them to be somehow reducible to descriptions, then there is no explanation at all (consistent with compositionality) for how a sense can be singular and, hence, determine a singular reference (as opposed to a concept) in the Fregean semantics.

\section{REFERENCES}

ATLAS, J. "Frege's polymorphous concept of presupposition and its role on a theory of meaning". Semantikos I, pp. 29-44, 1975.

BARWISE, J., COOPER, R. "Generalized Quantifiers and Natural Languages". Linguistics and Philosophy 4, pp. 159-219, 1981.

BEANEY, M. The Frege Reader. Oxford: Blackwell, 1997.

CAPPELEN, H., and LEPORE, E. Insensitive Semantics. New york: Oxford University Press, 2005.

DONNELLAN, K. "Reference and definite Descriptions". The Philosophical Review 75 (1966), pp. 281-304. Reprinted in Almog, J. and Leonardi, P (eds.), Essays on Reference, Language and Mind. Oxford: Oxford University Press, 2012. 1966, pp. 3-32.

DONNELLAN, K. "Proper Names and Identifying Descriptions”. Synthese 21, pp. 335-58. Reprinted in Almog, J. and Leonardi, P (eds.), Essays on Reference, Language and Mind. Oxford: Oxford University Press, 2012. 1970, pp. 49-79.

DUMMETT, M. Frege. Philosophy of Language. Cambridge, Mass.: Harvard University Press, 1973.

EVANS, G. The Varieties of Reference. Oxford: Oxford University Press, 1982. 
Von FINTEL, K. "Would You Believe It? The King of France is Back! (Presupposition and TruthValue Intuitions). In Reimer, M., and Bezuidenhout, A. (eds.). Descriptions and Beyond. New York: Oxford University Press, 2004. 2004, pp. 315-41.

FREGE, G. "Über Sinn und Bedeutung”. Zeitschrift für Philosophie und philosophische Kritik 100, pp. 25-50. Translated by Black, M., and reprinted in Beaney (1997). 1892, pp. 151-71.

FREGE, G. Die Grundgesetze der Arithmetik (Vol. I). Jena: Pohle, 1893.

FREGE, G. Nachgelassene Schriften. (NS). Ed. by H. Hermes, F. Kambartel and F. Kaulbach. Hamburg: Felix Meiner Verlag. (1979) Posthumous Writings. (PW). Transl. by Peter Long and Roger White. Oxford: Oxford University Press, 1976.

HILBERT, D., and BERNAYS, P. Grundlagen der Mathematik I. Heidelberg: Springer Verlag, 1934.

HAWTHORNE, J., and MANLEY, D. The Reference Book. New York: Oxford University Press, 2010.

KARTTUNEN, L. "Presuppositions of Compound Sentences". Linguistic Inquiry IV, N. 2, 1973, pp. $169-93$.

KEENAN, E. "Two Kinds of Presupposition in Natural Language". In Fillmore, C. and Langendoen, D. (eds.) (1971). Studies in Linguistic Semantics, New York: Holt, Rinehart, and Winston. 1971, pp. 413-61.

KRIPKE, S. Naming and Necessity. Cambridge, Mass.: Harvard University Press, 1980.

LEVINGSON, S. Pragmatics. New York: Cambridge University Press, 1983.

NEALE, S. Descriptions. Cambridge, Mass.: The MIT Press/Bradford Books, 1990.

RUFFINO, M. “Context and Quantifier Domain”. Manuscrito 32, n. 1, 2009, pp. 283-308.

RUFFINO, M. “Dominios Quantificacionales e Intención del Hablante”. Orlando. E. (ed.), Significados en Contexto y Verdad Relativa. Ensayos Sobre Semántica y Pragmática. Buenos Aires: Título. 2015, pp. 77-98.

RUSSELL, B. “On Denoting”. Mind 14, N. 56, 1905, pp. 479-93.

RUSSELL, B. The Problems of Philosophy. London: Home University Library, 1912.

RUSSELL, B. "Mr. Strawson on Referring". In My Philosopjical Development. London: Allen and Unwin. 1959, 238-45.

SELLARS, W. "Presupposing”. The Philosophical Review 63, No. 2, 1954 , pp. 197-215.

SHANON, B. "On the Two Kinds of Presuppositions in Natural Language Language 14, No. 2, 1976, pp. 247-9.

STANLEY, J., and Szabó, Z. "On Quantifier Domain restriction”. Mind and Language 15, 2000 , pp. 219-61.

SOAMES, S. A Critical Examination of Frege's Theory of Presupposition and Contemporary Alternatives. Ph.D. Dissertation, M.I.T, 1976. 
STALNAKER, R. "Pragmatics". Synthese 22, I/2, 1970 , pp. 272-89.

STRAWSON, P. “On Referring”. Mind, New Series, 59, No. 235, 1950 , pp. 320-44.

STRAWSON,. P. “A Reply to Mr. Sellars”. The Philosophical Review 63, No. 2, 1954, pp. 216-31.

Recebido: $28 / 02 / 2017$

Aceito: $28 / 03 / 2017$ 